Vietnam Academy of Science and Technology
Vietnam Journal of Earth Sciences
http://www.vjs.ac.vn/index.php/jse

\title{
A study on the variation of zeta potential with mineral composition of rocks and types of electrolyte
}

\author{
Luong Duy Thanh*1, Rudolf Sprik ${ }^{2}$ \\ ${ }^{I}$ Thuy Loi University, 175 Tay Son, Dong Da, Ha Noi, Vietnam \\ ${ }^{2}$ Van der Waals-Zeeman Institute, University of Amsterdam, The Netherlands
}

Received 11 February 2017; Received in revised form 11 September 2017; Accepted 13 January 2018

\begin{abstract}
Streaming potential in rocks is the electrical potential developing when an ionic fluid flows through the pores of rocks. The zeta potential is a key parameter of streaming potential and it depends on many parameters such as the mineral composition of rocks, fluid properties, temperature etc. Therefore, the zeta potential is different for various rocks and liquids. In this work, streaming potential measurements are performed for five rock samples saturated with six different monovalent electrolytes. From streaming potential coefficients, the zeta potential is deduced. The experimental results are then explained by a theoretical model. From the model, the surface site density for different rocks and the binding constant for different cations are found and they are in good agreement with those reported in literature. The result also shows that (1) the surface site density of Bentheim sandstone mostly composed of silica is the largest of five rock samples; (2) the binding constant is almost the same for a given cation but it increases in the order $K_{\mathrm{Me}}\left(\mathrm{Na}^{+}\right)<K_{\mathrm{Me}}\left(\mathrm{K}^{+}\right)<K_{\mathrm{Me}}\left(\mathrm{Cs}^{+}\right)$for a given rock.
\end{abstract}

Keywords: streaming potential; zeta potential; porous media; rocks; electrolytes.

C2018 Vietnam Academy of Science and Technology

\section{Introduction}

Streaming potential has been used for a variety of geophysical applications. For instance, the streaming potential is used to map subsurface flow and detect subsurface flow patterns in oil reservoirs (e.g., Wurmstich and Morgan, 1994); in geothermal exploration (e.g., Corwin and Hoovert, 1979) or in detection of water leakage through dams, dikes, reservoir floors, and canals (e.g., Ogilvy et al., 1969). The key parameter that controls the degree of the coupling between the ground

"Corresponding author, Email: luongduythanh2003@yahoo.com fluid flow in rocks and the electrical signals is the streaming potential coefficient. The zeta potential of a solid-liquid interface of porous media is one of the most crucial parameters in streaming potential coefficient. Most rocks made of various types of mineral composition are filled or partially filled with natural water containing different electrolytes. The influence of the mineral composition of rocks and electrolyte types on the zeta potential has been studied (Luong and Sprik, 2016a). However, the surface site density for different rocks and the binding constant for different cations have not yet obtained in Luong and Sprik (2016a). In this work, the similar approach is per- 
formed for other types of rock to obtain those parameters. Measurements of streaming potential are performed for five consolidated rock samples (one sample of Bentheim sandstone, two samples of Berea sandstone and two samples of artificial ceramic) saturated by six monovalent electrolytes (NaI, $\mathrm{NaCl}, \mathrm{KI}, \mathrm{KCl}, \mathrm{KNO}_{3}$ and $\mathrm{CsCl}$ ). The reason to select five rock samples used this work is that they are silica rich rocks. Therefore, the experimental data can be analyzed and compared to a theoretical model developed for silica surfaces. The electrolyte concentration of $10^{-3} \mathrm{M}$ is used in this work because that value is comparable to the groundwater as stated by Jackson et al. (2012). From streaming potential coefficients, the zeta potential is obtained for different systems of electrolyte and rock. The measured zeta potential is then compared with the theoretical model. The surface site density for different rocks and the binding constant for different cations are then obtained.

\section{Theoretical background of streaming potential}

The liquid flow in rocks is a reason for a measurable electrical potential due to the electrokinetic effect. The resulting electrical potential is called the streaming potential. Streaming potential is directly connected to an electric double layer (EDL) that exists at the solid-liquid interface. Solid grain surfaces of the rocks immersed in aqueous systems acquire a surface electric charge, mainly via the dissociation of silanol groups - $>\mathrm{SiOH}^{0}$ (where $>$ means the mineral lattice and the superscript " 0 " means zero charge) and the adsorption of cations on solid surfaces. The reactions at a solid silica surface (silica is the main component of rocks) in contact with fluids have been well described in the literature (e.g., Revil and Glover, 1997; Behrens and Grier, 2001; Glover et al., 2012). The reactions at the silanol surfaces in contact with 1:1 electrolyte solutions are:

$$
>\mathrm{SiOH}^{0} \Leftrightarrow>\mathrm{SiO}^{-}+\mathrm{H}^{+},
$$

for deprotonation of silanol groups and $>\mathrm{SiOH}^{0}+\mathrm{Me}^{+} \Leftrightarrow>\mathrm{SiOMe}^{0}+\mathrm{H}^{+}$, for cation adsorption on silica surfaces $\left(\mathrm{Me}^{+}\right.$ refer to monovalent cations in the electrolytes such as $\mathrm{K}^{+}$or $\mathrm{Na}^{+}$). It should be noted that further protonation of the silanol surfaces is expected only under extremely acidic conditions $(\mathrm{pH}<2-3)$ and is not considered. Similarly, the protonation of doubly coordinated groups $\left(>\mathrm{Si}_{2} \mathrm{O}^{0}\right)$ is not taken into account because these are normally considered inert (e.g., Revil and Glover, 1997; Behrens and Grier, 2001; Glover et al., 2012). According to Revil and Glover, 1997 and Glover et al., 2012, the disassociation constant for deprotonation of the silica surfaces is $\mathrm{d}$ termined as $K_{(-)}=\frac{\Gamma_{S i O^{-}}^{0} . \alpha_{H^{+}}^{0}}{\Gamma_{\mathrm{SiOH}}^{0}}$,

and the binding constant for cation adsorption on the silica surfaces is determined $K_{M e}=\frac{\Gamma_{\mathrm{SiOMe}}^{0} \cdot \alpha_{H^{+}}^{0}}{\Gamma_{\mathrm{SiOH}}^{0} \cdot \alpha_{M e^{+}}^{0}}$

where $\Gamma_{i}^{0}$ is the surface site density of surface species $i\left(\operatorname{sites} / \mathrm{m}^{2}\right)$ and $\alpha_{i}^{0}$ is the activity of an ionic species $i$ at the closest approach of the mineral surface (no units).

The total density of surface sites $\left(\Gamma_{S}^{0}\right)$ is determined as follows

$$
\Gamma_{S}^{0}=\Gamma_{S i O H}^{0}+\Gamma_{S i O^{-}}^{0}+\Gamma_{\text {SiOMe }}^{0}
$$

Based on Eq. (3), Eq. (4) and Eq. (5), the surface site density of sites $\Gamma_{S i O^{-}}^{0}$ and $\Gamma_{\text {SiOMe }}^{0}$ are obtained (see Revil and Glover, 1997 or Glover et al., 2012 for more details). The mineral surface charge density $Q_{S}^{0}$ in $\mathrm{C} / \mathrm{m}^{2}$ can be found by

$$
Q_{S}^{0}=-e . \Gamma_{S i O^{-}}^{0}
$$

where $e$ is the elementary charge. 
Due to a charged solid surface, an electric double layer (EDL) is developed at the liquidsolid interface when solid grains of rocks are in contact with the liquid. The EDL is made up of (1) the Stern layer where cations are adsorbed on the surface and are immobile due to the strong electrostatic attraction and (2) the diffuse layer where the number of cations exceeds the number of anions and the ions are mobile (see Figure 1). The distribution of ions and the electric potential within the EDL is shown in Figure 1 for a broad planar interface (e.g., Stern, 1924; Ishido and Mizutani, 1981). The closest plane to the solid surface in the diffuse layer at which flow occurs is termed the shear plane and the electrical potential at this plane is called the zeta potential $(\zeta)$.

The electrical potential distribution $\varphi$ in the EDL has, approximately, an exponential distribution as follows (Revil and Glover,

$$
\varphi_{d}=\frac{2 k_{b} T}{3 e} \ln \left\{\frac{\sqrt{8.10^{3} \varepsilon_{o} \varepsilon_{r} k_{b} T N}\left(10^{-p H}+K_{M e} C_{f}\right)}{2 e \Gamma_{S}^{0} K_{(-)}}\left[\frac{C_{f}+10^{-p H}+10^{p H-p K_{w}}}{\sqrt{C_{f}}}\right]\right\}
$$

and $\chi_{d}$ is the Debye length (m) given by

$$
\chi_{d}=\sqrt{\frac{\varepsilon_{o} \varepsilon_{r} k_{b} T}{2000 N e^{2} C_{f}}},
$$

and $\chi$ is the distance from the mineral surface $(\mathrm{m})$. The zeta potential $(\mathrm{V})$ is then be calculated as

$$
\zeta=\varphi_{d} \exp \left(-\frac{\chi_{\zeta}}{\chi_{d}}\right)
$$

where $\chi_{\zeta}$ is the shear plane distance - the distance from the mineral surface to the shear plane and that is normally taken as $2.4 \times 10^{-10}$ $\mathrm{m}$ (Glover et al., 2012).

In Eq. (8) and Eq. (9), $k_{b}$ is the Boltzmann's constant $\left(1.38 \times 10^{-23} \mathrm{~J} / \mathrm{K}\right.$ (Lide, 2009)), $\varepsilon_{0}$ is the dielectric permittivity in vacuum $\left(8.854 \times 10^{-12} \mathrm{~F} / \mathrm{m}\right.$ (Lide, 2009)), $\varepsilon_{r}$ is the relative permittivity (no units), $T$ is temperature (in $\mathrm{K}$ ), $e$ is the elementary charge $\left(1.602 \times 10^{-19} \mathrm{C}\right.$ (Lide, 2009)), $N$ is the Avogadro's number $\left(6.022 \times 10^{23} / \mathrm{mol}\right.$ (Lide,
1997; Glover et al., 2012):

$$
\varphi=\varphi_{d} \exp \left(-\frac{\chi}{\chi_{d}}\right)
$$

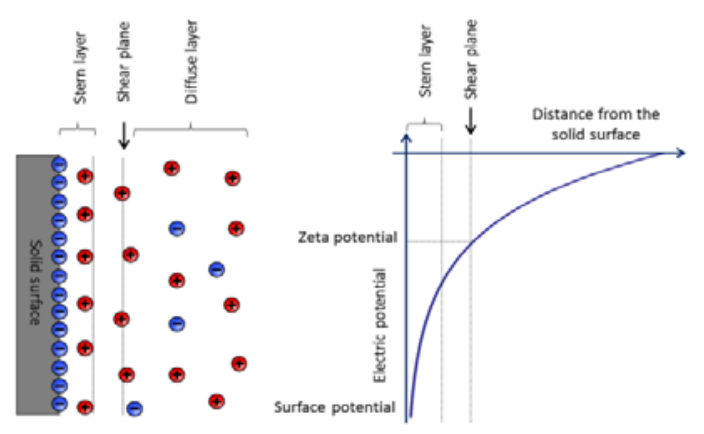

Figure 1. Stern model for the charge and electric potential distribution in the EDL at a solid-liquid interface (e.g., Stern, 1924; Ishido and Mizutani, 1981)

2009)), $C_{f}$ is the electrolyte concentration $(\mathrm{mol} / \mathrm{L}), p H$ is the fluid $\mathrm{pH}, \Gamma_{S}^{0}$ is the surface site density $\left(\right.$ sites $\left./ \mathrm{m}^{2}\right)$ and $K_{w}$ is the disassociation constant of water (no units).

The different flows (fluid flow, electrical flow, heat flow etc.) are coupled by an equation (Onsager, 1931).

$$
\mathbf{J}_{i}=\sum_{j=1}^{n} L_{i j} \mathbf{X}_{j}
$$

which links the forces $\mathbf{X}_{j}$ to the macroscopic fluxes $\mathbf{J}_{i}$ through transport coupling coefficients $L_{i j}$.

Considering the coupling between the hydraulic flow and the electrical flow in porous media, assuming no concentration gradients and no temperature gradient, the electric current density $\mathbf{J}_{\mathrm{e}}\left(\mathrm{A} / \mathrm{m}^{2}\right)$ and the flow of fluid $\mathbf{J}_{\mathrm{f}}(\mathrm{m} / \mathrm{s})$ can be written as (Jouniaux and Ishido, 2012):

$$
\begin{aligned}
& \mathbf{J}_{\mathrm{e}}=-\sigma_{0} \nabla V-L_{e k} \nabla P . \\
& \mathbf{J}_{\mathrm{f}}=-L_{e k} \nabla V-\frac{k_{0}}{\eta} \nabla P,
\end{aligned}
$$


where $P$ is the pressure that drives the flow $(\mathrm{Pa}), V$ is the electrical potential $(\mathrm{V}), \sigma_{0}$ is the bulk electrical conductivity, $k_{0}$ is the bulk permeability $\left(\mathrm{m}^{2}\right), \eta$ is the dynamic viscosity of the fluid (Pa.s), and $L_{e k}$ is the electrokinetic coupling $\left(\mathrm{A} \cdot \mathrm{Pa}^{-1} \cdot \mathrm{m}^{-1}\right)$. The electrokinetic coupling coefficient is the same in Eq. (12) and Eq. (13) because the coupling coefficients must comply with the Onsager's reciprocal equation in the steady state. From these equations, it is seen that even if there is no applied potential difference $(\nabla V=0)$, then simply the presence of a pressure difference can produce an electric current. On the other hand, if no pressure difference is applied ( $\nabla P$ $=0$ ), the presence of an electric potential difference can generate a flow of fluid.

The streaming potential coefficient (SPC) is defined when the total electric current density $\mathbf{J}_{\mathrm{e}}$ is zero, leading to (Jouniaux and Ishido, 2012):

$$
C_{S}=\frac{\Delta V}{\Delta P}=-\frac{L_{e k}}{\sigma_{0}}
$$

This SPC can be determined by setting up a pressure difference $\Delta P$ across a porous medium and measuring the electric potential difference $\Delta V$. In the case of a unidirectional flow through a porous medium, this coefficient is written as (e.g., Mizutani et al., 1976, Jouniaux and Ishido, 2012)

$$
C_{S}=\frac{\varepsilon_{r} \varepsilon_{o} \zeta}{\eta \sigma_{e f f}}
$$

where $\zeta$ is the zeta potential and $\sigma_{\text {eff }}$ is the effective conductivity which includes the fluid conductivity and the surface conductivity. The SPC can also be expressed as

$$
C_{S}=\frac{\varepsilon_{r} \varepsilon_{o} \zeta}{\eta F \sigma_{r}}
$$

where $\sigma_{r}$ is the electrical conductivity of the saturated rocks and $F$ is the formation factor.

\section{Experiment}

Measurements are carried out for five rock samples with six monovalent electrolytes ( $\mathrm{NaI}, \mathrm{NaCl}, \mathrm{KI}, \mathrm{KCl}, \mathrm{KNO}_{3}$, and $\mathrm{CsCl}$ ) at the concentration of $10^{-3} \mathrm{M}$. The samples are cylindrical cores of Bentheim sandstone $(\mathrm{BEN})$, Berea sandstone (BS1 and BS5) and artificial ceramic (DP46i and DP50). The mineral composition, microstructure parameters and sources of the rock samples have been reported in Luong (2014) and reshown in Table 1.

Table 1. Mineral composition and microstructure parameters of the rocks. Symbols $k_{o}$ (in $\mathrm{mD}$ ), $\phi$ (in \%), $F$ (no units),

\begin{tabular}{|c|c|c|c|c|c|c|}
\hline Samples & Mineral composition & $k_{o}$ & $\Phi$ & $F$ & $\alpha_{\infty}$ & $\rho_{s}$ \\
\hline $\mathrm{BEN}$ & Mostly Silica (Tchistiakov, 2000) & 1382 & 22.3 & 12.0 & 2.7 & 2638 \\
\hline DP46i & $\begin{array}{l}\text { Mainly Alumina and fused silica } \\
\text { (see: www.tech-ceramics.co.uk ) }\end{array}$ & 4591 & 48.0 & 4.7 & 2.3 & 3559 \\
\hline DP50 & $\begin{array}{l}\text { Mainly Alumina and fused silica } \\
\text { (see: www.tech-ceramics.co.uk ) }\end{array}$ & 2960 & 48.5 & 4.2 & 2.0 & 3546 \\
\hline BS5 & $\begin{array}{l}\text { Mainly Silica and Alumina, Ferric Oxide } \\
\text { (www.bereasandstonecores.com ) }\end{array}$ & 310 & 20.1 & 14.5 & 2.9 & 2514 \\
\hline BS1 & $\begin{array}{l}\text { Mainly Silica and Alumina, Ferric Oxide } \\
\text { (www.bereasandstonecores.com ) }\end{array}$ & 120 & 14.5 & 19.0 & 2.8 & 2602 \\
\hline
\end{tabular}
$\alpha_{\infty}$ (no units), $\rho_{s}$ (in $\mathrm{kg} / \mathrm{m}^{3}$ ) stand for permeability, porosity, formation factor, tortuosity and solid density of porous media, respectively

The experimental setup and the approach used to collect the SPC are well described in Luong (2014) or Luong and Sprik (2016a, $2016 \mathrm{~b})$. The electrolytes are pumped through the samples until the electrical conductivity and $\mathrm{pH}$ of the solutions get a stable value measured by a multimeter (Consort C861). The equilibrium solution $\mathrm{pH}$ is measured in the range 6.0 to 7.5. Electrical potential differences across the samples are measured by a multimeter (Keithley Model 2700). Pressure differences between a sample are 
measured by a pressure transducer (Endress and Hauser Deltabar S PMD75). The measmeasured electrical potential difference is then plotted as a function of the applied pressure difference. Consequently, the SPC is obtained by calculating the straight line slope.

\section{Results and Discussions}

Figure 2 shows three typical sets of the streaming potential as a function of pressure difference for the Bentheim sandstone (BEN). It is shown that there is a very small drift of the streaming potential over time and the straight lines fitting the experimental data may not go through the origin. The reason may be due to the electrode polarization. The SPC is then taken as the average value of the slope of three straight lines. The maximum error of the SPC is $10 \%$. It is found that the SPC is negative regardless of types of electrolyte for all samples. From the measured SPC, the variation of the SPC in magnitude with types of electrolyte and types of rock is shown in Figure 3.

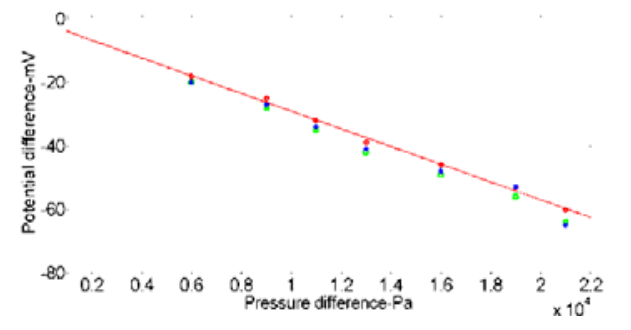

Figure 2. Streaming potential as a function of pressure difference for the $\mathrm{BEN}$ sample saturated by $\mathrm{NaCl}$ electrolyte

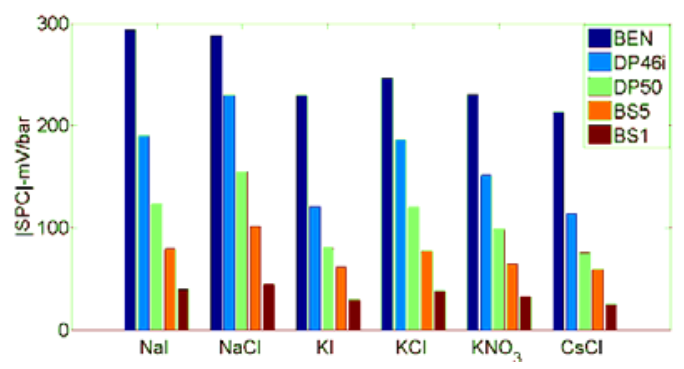

Figure 3. The variation of the SPC with types of electrolyte and types of rocks
The electrical conductivity of the saturated samples is deduced from the sample resistances that are measured by an impedance analyzer (Luong, 2014). Therefore, the zeta potential will be determined by Eq. (16) in which viscosity, relative permittivity of electrolyte solutions and the formation factor of the samples are already known. The obtained zeta potential is reported in Table 2 . The variation of the zeta potential with electrolyte types and rock types is shown in Figure 4. The results show that types of rocks and types of electrolytes have a strong influence on the zeta potential. This can be qualitatively explained by the difference of the surface site density, the disassociation constant of the surface sites from rock sample to rock sample as well as the binding constant of cations. For example, the binding constant of $\mathrm{Na}^{+}$is smaller than $\mathrm{K}^{+}$(Glover et al., 2012; Dove and Rimstidt, 1994). Therefore, at the same electrolyte concentration, less cations of $\mathrm{Na}^{+}$are absorbed on the negative solid surface than cations of $\mathrm{K}^{+}$. Consequently, the zeta potential is larger in the electrolyte containing cations of $\mathrm{Na}^{+}$than that of $\mathrm{K}^{+}$. Among the electrolytes tested in this work, $\mathrm{NaI}$ has the most effect on the zeta potential, while the $\mathrm{CsCl}$ has the least for all samples. This observation is the same as what is stated in Kim et al. (2004) for the zeta potential of silica particles in electrolytes of $\mathrm{NaCl}, \mathrm{NaI}$, $\mathrm{KCl}, \mathrm{CsCl}$, CsI.

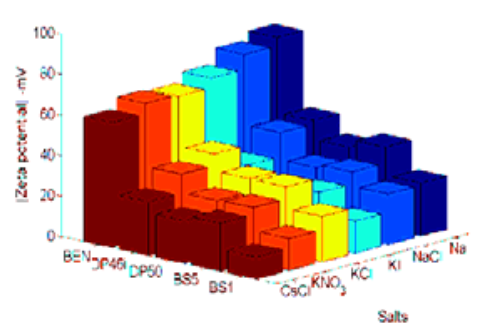

Figure 4. The variation of the zeta potential with types of electrolyte and types of rock 
Luong Duy Thanh, et al./Vietnam Journal of Earth Sciences 40 (2018)

Table 2. Zeta potential for different electrolytes and different rocks $(\mathrm{mV})$

\begin{tabular}{|c|c|c|c|c|c|}
\hline & BEN & DP46i & DP50 & BS5 & BS1 \\
\hline $\mathrm{NaCl}$ & -78.1 & -46.5 & -36.2 & -40.0 & -26.1 \\
\hline $\mathrm{NaI}$ & - 84.3 & -43.2 & -30.1 & -32.0 & -25.0 \\
\hline $\mathrm{KI}$ & -70.7 & -31.7 & -22.7 & -26.2 & -15.8 \\
\hline $\mathrm{KCl}$ & -65.9 & -41.5 & -33.9 & -33.0 & -22.4 \\
\hline $\mathrm{KNO}_{3}$ & -66.7 & -35.8 & -26.5 & -27.2 & -15.6 \\
\hline $\mathrm{CsCl}$ & -61.4 & -26.5 & -20.3 & -23.5 & -10.8 \\
\hline
\end{tabular}

To quantitatively explain the behaviors in Figure 4, the theoretical model that has been introduced in section 2 is applied. For Bentheim sandstone made of mainly silica, input parameters available in Glover et al. (2012) for silica is used. The value of the disassociation constant $K_{(-)}$is taken as $10^{-7.1}$. The shear plane distance $\chi_{\zeta}$ is taken as $2.4 \times 10^{-10} \mathrm{~m}$. The surface site density $\Gamma_{S}^{0}$ is taken as $5 \times 10^{18}$ site $/ \mathrm{m}^{2}$. The disassociation constant of water $K_{w}$ is taken as $9.22 \times 10^{-15}$ at $22^{\circ} \mathrm{C}$. The fluid $\mathrm{pH}$ is taken as average value of 6.7 (between 6 and 7.5). The binding constant for cation adsorption on silica is not well known. For example, Glover et al. (2012) reported that $K_{\mathrm{Me}}\left(\mathrm{Na}^{+}\right)=10^{-3.25}$ and $K_{\mathrm{Me}}\left(\mathrm{K}^{+}\right)=10^{-2.8}$. $K_{\mathrm{Me}}\left(\mathrm{Li}^{+}\right)=10^{-7.8}$ and $K_{\mathrm{Me}}\left(\mathrm{Na}^{+}\right)=10^{-7.1}$ are found for silica by Dove and Rimstidt (1994). $K_{\mathrm{Me}}\left(\mathrm{Li}^{+}\right)=10^{-7.7}, K_{\mathrm{Me}}\left(\mathrm{Na}^{+}\right)=10^{-7.5}$ and $K_{\mathrm{Me}}\left(\mathrm{Cs}_{+}\right)=10^{-7.2}$ are given by Kosmulski and Dahlsten (2006). In order to obtain the binding constant for Bentheim sandstone used in this work, the experimental data is fitted in combination with the theoretical models (see Figure 5). From that, the binding constants for cations of $\mathrm{Na}^{+}, \mathrm{K}^{+}$and $\mathrm{Cs}^{+}$are found to be $K_{\mathrm{Me}}\left(\mathrm{Na}^{+}\right)=10^{-5.0}, K_{\mathrm{Me}}\left(\mathrm{K}^{+}\right)=10^{-3.3}, K_{\mathrm{Me}}\left(\mathrm{Cs}^{+}\right)$ $=10^{-3.2}$, respectively.

For other samples, Luong and Sprik (2016a) show that the disassociation constant has much less influence on the zeta potential than the surface site density and the binding constant. Therefore, all input parameters are kept the same as reported by Glover et al. (2012) except the surface site density and the binding constant. Using the same approach as mentioned above for Bentheim sandstone, the binding constants for cations of $\mathrm{Na}^{+}, \mathrm{K}^{+}, \mathrm{Cs}^{+}$ and surface site density for the other rocks are obtained (see Table 3). The binding constants deduced in this work for $\mathrm{Na}^{+}, \mathrm{K}^{+}$and $\mathrm{Cs}^{+}$are in good agreement with those reported by Scales (1990) in which $K_{\mathrm{Me}}\left(\mathrm{Na}^{+}\right)=10^{-5.5}$, $K_{\mathrm{Me}}\left(\mathrm{K}^{+}\right)=10^{-3.2}, K_{\mathrm{Me}}\left(\mathrm{Cs}^{+}\right)=10^{-2.8}$. Table 3 indicates that the surface site density of Bentheim sandstone (BEN) mostly composed of silica is the largest of five rock samples while it is the same order of magnitude for the rest of samples made of a mixture silica, alumina and Ferric oxide. It is also shown that the binding constant is almost the same for a given cation but it increases in the order $K_{\mathrm{Me}}\left(\mathrm{Na}^{+}\right)<K_{\mathrm{Me}}\left(\mathrm{K}^{+}\right)<K_{\mathrm{Me}}\left(\mathrm{Cs}^{+}\right)$for a given rock.

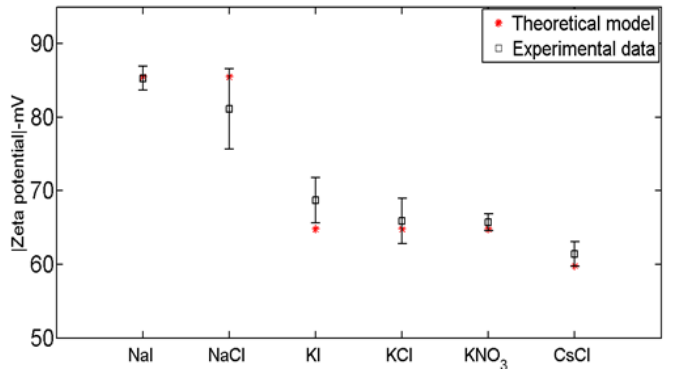

Figure 5. The value of the zeta potential as a function of electrolytes for Bentheim sandstone (BEN) from both the experimental data and the model

Table 3. Surface site density and binding constant obtained by fitting experimental data

\begin{tabular}{llllll}
\hline & BEN & DP46i & DP50 & BS5 & BS1 \\
\cline { 2 - 6 }$\Gamma_{S}^{0}\left(\mathrm{site} / \mathrm{m}^{2}\right)$ & $5 \times 10^{18}$ & $0.7 \times 10^{18}$ & $0.4 \times 10^{18}$ & $0.4 \times 10^{18}$ & $0.15 \times 10^{18}$ \\
$K_{\mathrm{Me}}\left(\mathrm{Na}^{+}\right)$ & $10^{-5.0}$ & $10^{-4.5}$ & $10^{-4.5}$ & $10^{-4.5}$ & $10^{-4.5}$ \\
$K_{\mathrm{Me}}\left(\mathrm{K}^{+}\right)$ & $10^{-3.3}$ & $10^{-3.4}$ & $10^{-3.5}$ & $10^{-3.5}$ & $10^{-3.9}$ \\
$K_{\mathrm{Me}}\left(\mathrm{Cs}^{+}\right)$ & $10^{-3.2}$ & $10^{-3.2}$ & $10^{-3.2}$ & $10^{-3.3}$ & $10^{-3.5}$ \\
\hline
\end{tabular}


The variation of the zeta potential with the binding constant is predicted from the theoretical model $\left(K_{(-)}=10^{-7.1} ; \chi_{\zeta}=2.4 \times 10^{-10} \mathrm{~m}\right.$; $\Gamma_{S}^{0}=5 \times 10^{18}$ site $/ \mathrm{m}^{2} ; K_{w}=9.22 \times 10^{-15} ; C_{f}=$ $\left.10^{-3} \mathrm{M}\right)$ for two different values of $\mathrm{pH}(\mathrm{pH}=$ 6.5 and $\mathrm{pH}=7.5$ ) as shown in Figure 6. It is seen that the zeta potential in magnitude decreases with increasing binding constant as explained above. Additionally, the zeta potential in magnitude at the higher value of $\mathrm{pH}$ $(\mathrm{pH}=7.5)$ is predicted to be larger than that at lower $\mathrm{pH}(\mathrm{pH}=6.5)$ and that is in good agreement with what is reported in the literature (e.g., Kirby and Hasselbrink, 2004).

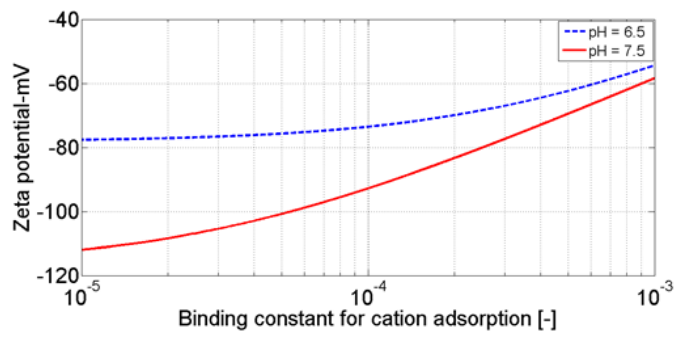

Figure 6. The variation of the zeta potential with the binding constant at two different values of $\mathrm{pH}$

\section{Conclusions}

In this work, streaming potential measurements are performed for five rock samples saturated with six different electrolytes. From measured streaming potential coefficients, the zeta potential is deduced. The theoretical model is then used to explain the experimental data. Based on the model, the surface site density for different rocks and the binding constant for different cations are found and they are in good agreement with those reported in the literature. It is also shown that (1) the surface site density of Bentheim sandstone mostly composed of silica is the largest of five rock samples while it is in the same order of magnitude for the rest of samples that are made of a mixture silica, alumina and Ferric oxide and (2) the binding constant is almost the same for a given cation but it increases in the order $K_{\mathrm{Me}}\left(\mathrm{Na}^{+}\right)<K_{\mathrm{Me}}\left(\mathrm{K}^{+}\right)<K_{\mathrm{Me}}\left(\mathrm{Cs}^{+}\right)$for a given rock. Additionally, the variation of the zeta potential with the binding constant is also predicted and the prediction is consistent with published works.

\section{References}

Corwin R.F., Hoovert D.B., 1979. The self-potential method in geothermal exploration. Geophysics 44, 226-245.

Dove P.M., Rimstidt J.D., 1994. Silica-Water Interactions. Reviews in Mineralogy and Geochemistry 29, 259-308.

Glover P.W.J., Walker E., Jackson M., 2012. Streamingpotential coefficient of reservoir rock: A theoretical model. Geophysics, 77, D17-D43.

Ishido T. and Mizutani H., 1981. Experimental and theoretical basis of electrokinetic phenomena in rockwater systems and its applications to geophysics. Journal of Geophysical Research, 86, 1763-1775.

Jackson M., Butler A., Vinogradov J., 2012. Measurements of spontaneous potential in chalk with application to aquifer characterization in the southern UK: Quarterly Journal of Engineering Geology \& Hydrogeology, 45, 457-471.

Jouniaux L. and Ishido T., 2012. International Journal of Geophysics. Article ID 286107, 16p. Doi:10.1155/2012/286107.

Kim S.S., Kim H.S., Kim S.G., Kim W.S., 2004. Effect of electrolyte additives on sol-precipitated nano silica particles. Ceramics International, 30, 171-175.

Kirby B.J. and Hasselbrink E.F., 2004. Zeta potential of microfluidic substrates: 1. Theory, experimental techniques, and effects on separations. Electrophoresis, 25, 187-202.

Kosmulski M., and Dahlsten D., 2006. High ionic strength electrokinetics of clay minerals. Colloids and Surfaces, A: Physicocemical and Engineering Aspects, 291, 212-218.

Lide D.R., 2009, Handbook of chemistry and physics, 90th edition: CRC Press.

Luong Duy Thanh, 2014. Electrokinetics in porous media, Ph.D. Thesis, University of Amsterdam, the Netherlands.

Luong Duy Thanh and Sprik R., 2016a. Zeta potential in porous rocks in contact with monovalent and diva- 


\section{Luong Duy Thanh, et al./Vietnam Journal of Earth Sciences 40 (2018)}

lent electrolyte aqueous solutions, Geophysics, 81, D303-D314.

Luong Duy Thanh and Sprik R., 2016b. Permeability dependence of streaming potential coefficient in porous media. Geophysical Prospecting, 64, 714-725.

Luong Duy Thanh and Sprik R., 2016c. Laboratory Measurement of Microstructure Parameters of Porous Rocks. VNU Journal of Science: MathematicsPhysics 32, 22-33.

Mizutani H., Ishido T., Yokokura T., Ohnishi S., 1976. Electrokinetic phenomena associated with earthquakes. Geophysical Research Letters, 3, 365-368.

Ogilvy A.A., Ayed M.A., Bogoslovsky V.A., 1969. Geophysical studies of water leakage from reservoirs. Geophysical Prospecting, 17, 36-62.

Onsager L., 1931. Reciprocal relations in irreversible processes. I. Physical Review, 37, 405-426.
Revil A. and Glover P.W.J., 1997. Theory of ionicsurface electrical conduction in porous media. Physical Review B, 55, 1757-1773.

Scales P.J., 1990. Electrokinetics of the muscovite micaaqueous solution interface. Langmuir, 6, 582-589.

Behrens S.H. and Grier D.G., 2001. The charge of glass and silica surfaces. The Journal of Chemical Physics, 115, 6716-6721.

Stern O., 1924. Zurtheorieder electrolytischendoppelschist. Z. Elektrochem, 30, 508-516.

Tchistiakov A.A., 2000. Physico-chemical aspects of clay migration and injectivity decrease of geothermal clastic reservoirs: Proceedings World Geothermal Congress, 3087-3095.

Wurmstich B., Morgan F.D., 1994. Modeling of streaming potential responses caused by oil well pumping. Geophysics, 59, 46-56. 